\section{Tongue and groove ( $v$-shaped) osteotomy in treatment of non-union of long bones - a novel surgical technique}

S Mukhopadhyay, N Vannet, R Morgan-Jones

Department of Orthopaedics, University Hospital of Wales, UK

\section{CORRESPONDENCE TO}

S Mukhopadhyay, E: sudiptomohan@doctors.org.uk

\section{BACKGROUND}

To treat long-bone non-unions it is important to create a stable mechanical environment in which fracture healing can take place securely. Interfaces such as transverse or step-cut osteotomy can still be improved. The method of tongue and groove osteotomy (Figure 1) described here is a viable option in difficult non-union surgery.

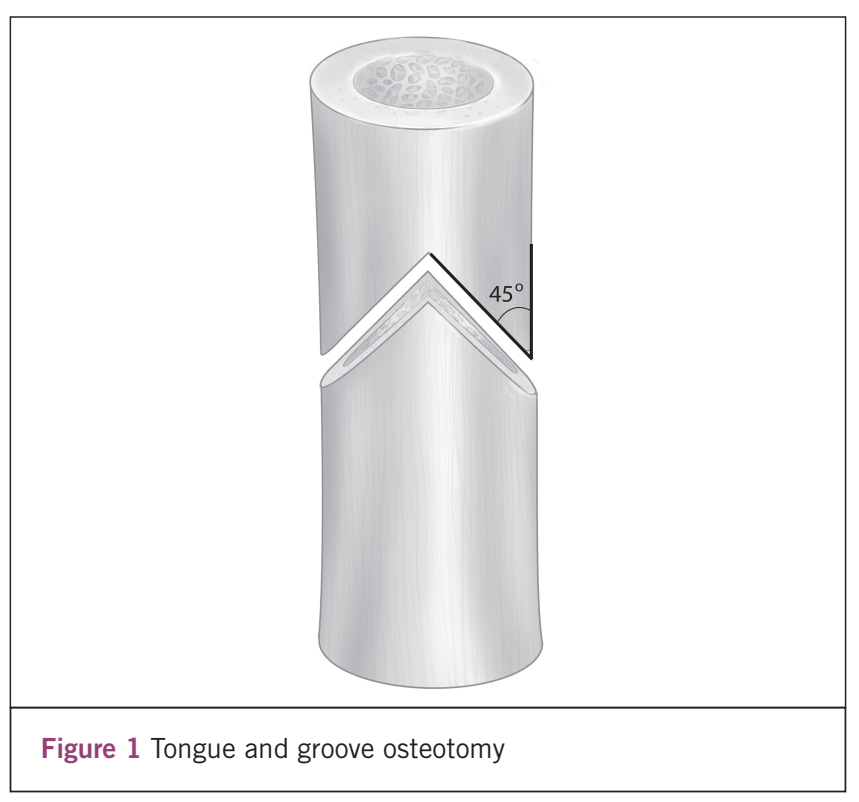

\section{METHODS}

Four patients treated for non-union of humerus (closed injury) and one for non-union of femur fracture (open injury leading to below-knee amputation) were followed up for 5 years (2003-2008).

After the fracture site was exposed and freshened, a 45-degree (Figure 1 ) tongue-shaped tower end was created at the proximal end of the distal fragment using an oscillating saw (Figure 2). On the distal part of the proximal end a corresponding 'groove' was made. Dynamic compression plating for humerus and intramedullary nailing for femur was used (Figures 3 and 4) with appropriate early postoperative mobilisation.
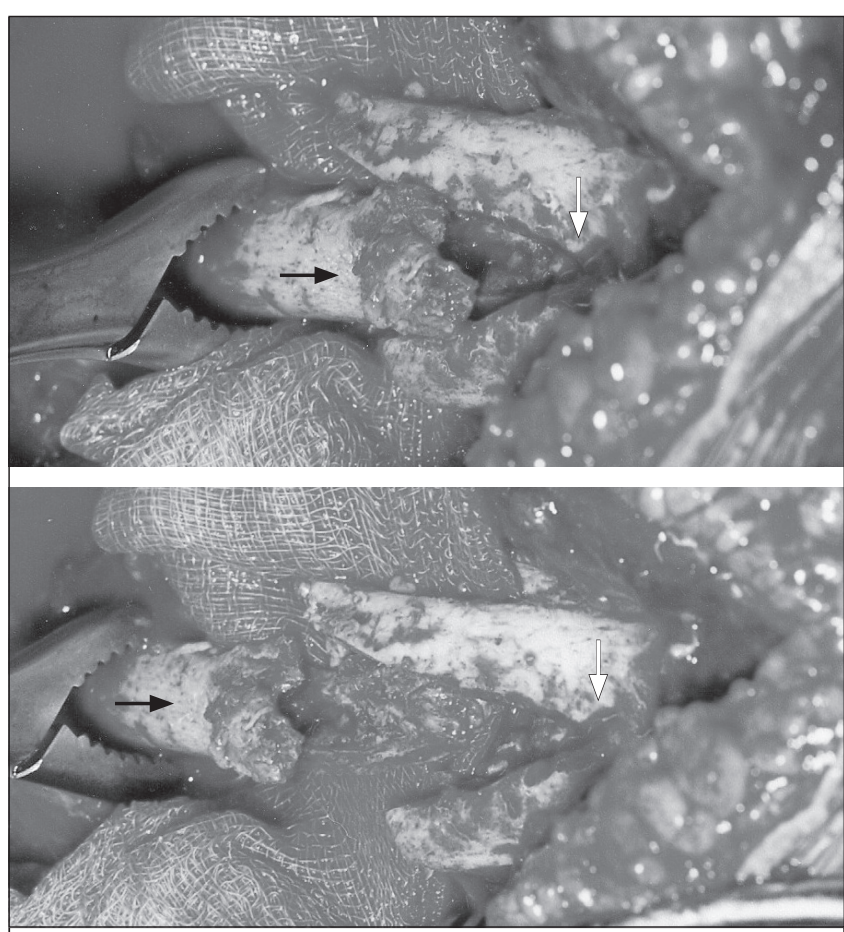

Figure 2 Intraoperative picture showing creation of tongue in groove (black arrow: tongue; white arrow: groove)
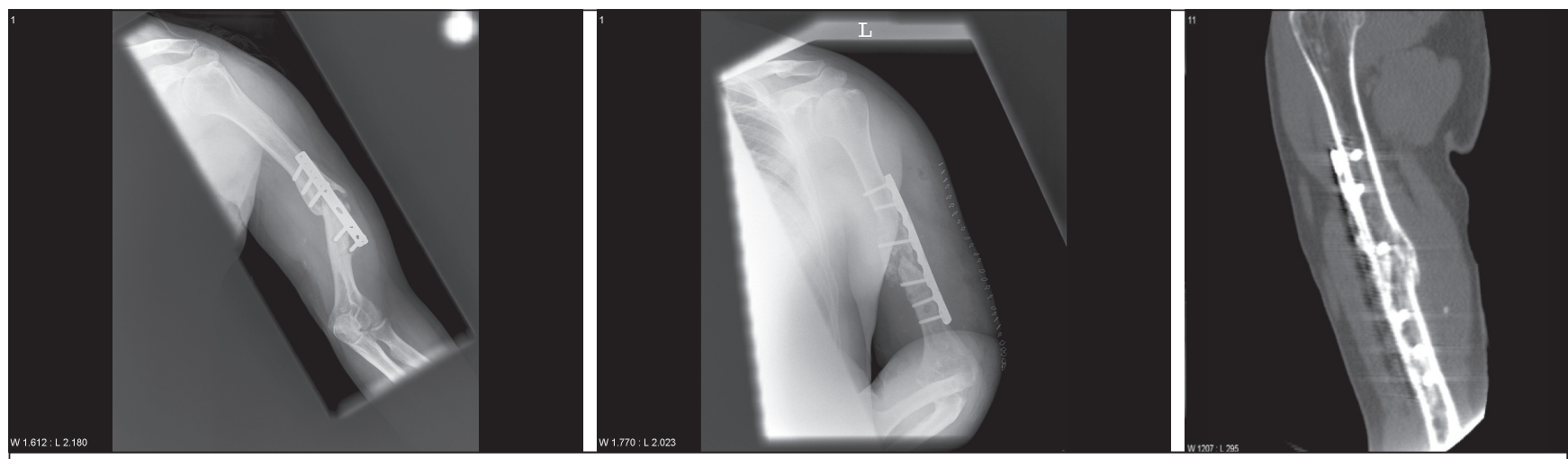

Figure 3 Pre and post-operative images with evidence of healing - humeral non-union 

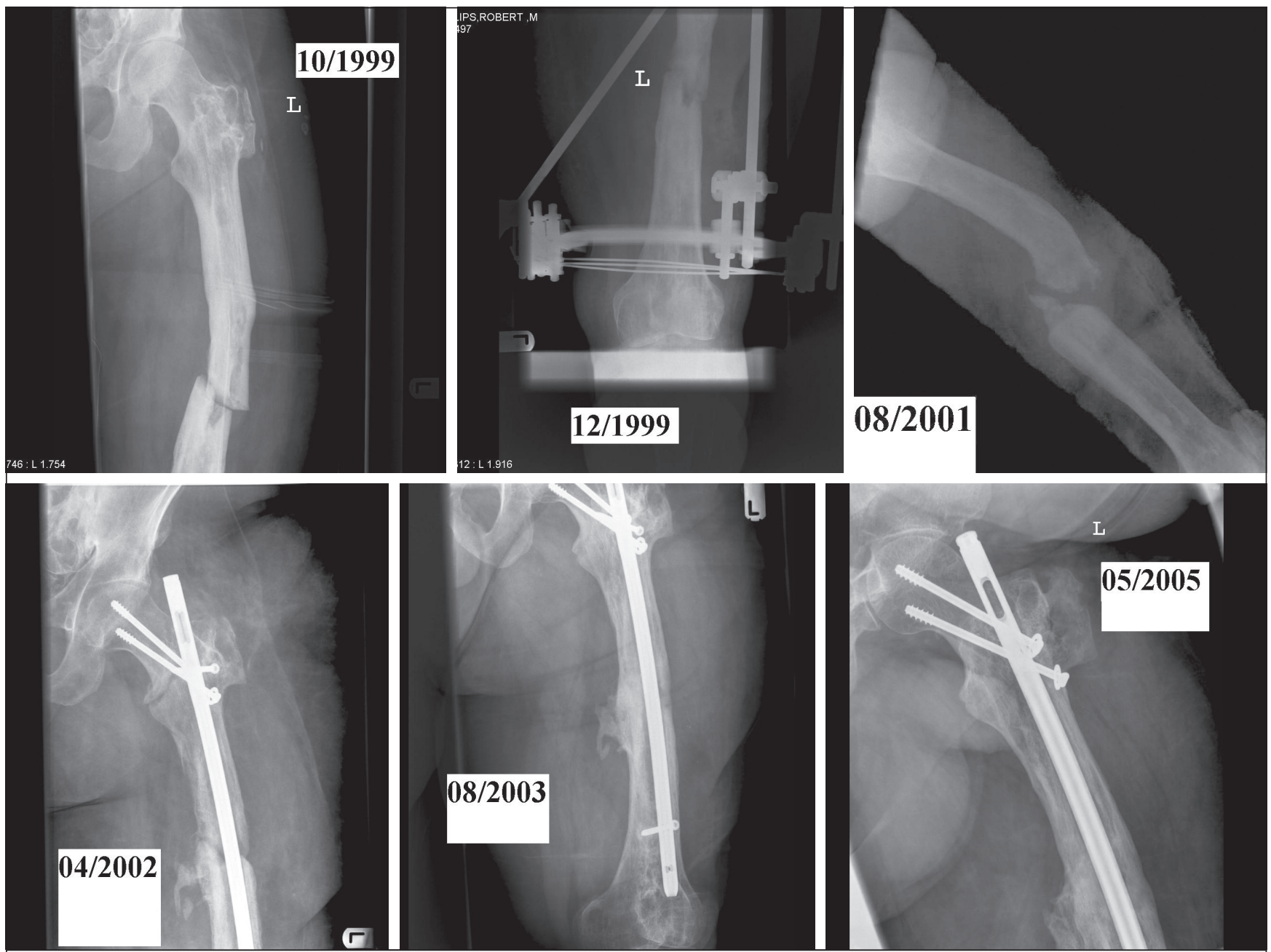

Figure 4 Pre and post-operative images with evidence of healing - femoral non-union

\section{DISCUSSION}

Humeral non-unions united between four and six months and the femoral non-union united in six months. Radiological signs of union were achieved earlier in each case than clinical union. Long-term follow-up showed satisfactory result in all cases.

In a study conducted with frozen porcine femur model it was observed that $\mathrm{v}$-shaped osteotomy with a docking angle between 45 and 90 degrees can withstand a strong compression load. ${ }^{1}$ The tongue-and-groove osteotomy in long-bone non-union surgery is better than step cut osteotomy because of increased contact surface area, improved rotational stability ${ }^{2-4}$ and easy reproducibility. Clinical results of similar surgical procedures are unavailable in the published English literature.

\section{References}

1. Lai DWT, Yip DKH, Li SJ et al. The dovetail configuration: a biomechanical analysis of a v-shaped osteotomy docking site. Journal of Musculoskeletal Research 2005; 9: 71-76.

2. Aro HT, Chao EY. Bone-healing patterns affected by loading, fracture fragment stability, fracture type, and fracture site compression. Clin Orthop Relat Res 1993; 293: 8-17.

3. Cascio BM, Thomas KA, Wilson SC. A mechanical comparison and review of transverse, step-cut, and sigmoid osteotomies. Clin Orthop Relat Res 2003; 411: 296-304.

4. Worlock P, Slack R, Harvey L, Mawhinney R. The prevention of infection in open fractures: an experimental study of the effect of fracture stability. Injury 1994; 25: 31-38. 